\title{
La universidad de cara al pueblo
}

\section{Cabezas, Rodrigo*}

Este acto de hoy intenté declinarlo por creer que el deber cumplido no busca como fin último reconocimientos o halagos, él es hijo del compromiso sustentado en valores e ideales. De otra parte, un acto de esta significación universitaria honra en profusión, y me hace interrogarme si he hecho lo suficiente para que mi querida universidad del Zulia me abrace con tanta plural solidaridad esta mañana.

Poco se cree en palabras de políticos. Pido la buena fe de ustedes para que crean las del universitario: Vengo con humildad y no poca pena a encontrarme con ustedes. Por adelante, excesivas gracias, en nombre de los que amo: mama, Nancy y mis hijos.

\section{La educación y la honestidad, el mejor patrimonio}

Hace más de una década, exactamente en 1990, creo que comenzó una etapa de mi vida que aun no concluye. Llegue al Parlamento Nacional de las manos de quien había sido mi profesor y maestro, el siempre recordado y siempre ejemplo, Luis Homez. Esa experiencia la he transitado sustentado en dos ideas básicas. La primera, representar dignamen- te los intereses del pueblo que te ha entregado, durante tres periodos constitucionales, el privilegio de ser uno de sus representantes; la segunda, actuar con responsabilidad y honestidad.

En cumplimiento de la primera, no he parado un segundo en buscar soluciones a los problemas del Zulia. He privilegiado en mi acción legislativa a la educación.

Sentí la obligación de que mi Universidad me tuviera como su mejor aliado, su mejor embajador en el viejo Congreso Nacional y en la novísima Asamblea Nacional. Cerca de treinta millardos de bolívares hemos logrado conseguir, en los últimos siete años, para el desarrollo académico y de planta física de LUZ. Ninguna otra Universidad Venezolana se aproxima a LUZ en esta materia. Y lo hicimos por creer en ella. Mas allá de sus complejidades internas, de sus autoridades, de sus posturas frente al Estado y la sociedad, emergía una universidad responsable que ha administrado pulcramente cada centavo de bolívar que el Gobierno Central le ha transferido para los proyectos y programas que líderiza FUNDADESARROLLO LUZ. ii Y ello honra y hace grande a La Universidad del Zulia!!!

Profesor de la Facultad de Ciencias Económicas y Sociales de la Universidad del Zulia (LUZ). 
El segundo carril me condujo a cumplir una máxima, que aspiro me acompañe hasta el final de mis responsabilidades como funcionario publico: Estamos donde nos puso el pueblo para servir siempre y nunca para servirnos. Que tremenda alegría me acompaña cuando puedo decir en la dirección de todos los vientos que no me he enriquecido, que no tengo negocios ni negociados con nadie, que he querido siempre hablar con autoridad moral frente a los alumnos de mi cátedra en mi querida Escuela de Economía, que he querido demostrar todos los días que se puede hacer "política" con honradez todo el tiempo y en todos los sitios. Que no solo se debe, sino que se puede tener a la honradez, la honestidad, la ética como el principal patrimonio, la principal y mas limpia bandera cuando se lucha por ideales y ya no importa uno sino los demás que entregan su confianza y esperanza para que nosotros las llevemos.

Por ello, afirmé al inicio de estas palabras que cuando se cumple con el deber ser, no se debe esperar homenajes; por ello, este acto, me compromete, me reafirma; siempre vale la pena librar batallas y si las aderezas con honradez y verdad, se puede decir que se vive o se vivió a plenitud, con y en la compañía de muchos.

\section{Conjurar en la universidad el temor al cambio}

Con el permiso de ustedes dejo unas ideas finales que creo pertinentes en este tiempo. Una breve reflexión universitaria entre universitarios.
En el marco de la necesaria relación entre el estado y la Universidad autónoma, entre la sociedad y la Universidad autónoma necesario es discutir a fondo el papel que ha jugado y el que debe asumir en el futuro inmediato la Universidad Venezolana y, LUZ en particular, frente a las transformaciones de hondo calado que se realizan en nuestro país.

Como universitario autonomista sostengo que el mundo académico se ha enajenado de la realidad histórica a tal punto que ha llegado a estar completamente de espaldas a procesos cuya irreversibilidad tienen aliento societario e histórico. Es absolutamente contradictorio que las casas de la ciencia, aquéllas que con plena libertad de cátedra puede oscultar, buscar y encontrar la verdad, no entienda que acá se cerro un ciclo de nuestra historia republicana y que vivimos los primeros años de uno nuevo, con hegemonías políticas nuevas, con elementos superestructurales en lo jurídico nuevo, entiéndase la constitución de 2000 y sus desarrollos incipientes. Que no capten elementos de transformación en la base material que nos conducen a una nueva economía y un nuevo posicionamiento de nuestro país en el concierto de naciones, en especial en el continente al que pertenecemos.

La universidad no puede seguir de espaldas a la historia. La universidad que es universidad por acuñar en su seno la ciencia, la técnica, la cultura, no puede interpretar el terremoto político que toca a sus puertas con los anteojos de los cronistas del día a día, con la rabia de los viejos privilegiados que ayer manejaban todos los hilos del poder político. 
La universidad Venezolana debe ser conjurada para que no le tema al cambio social que decidió el pueblo al que le sirve. Lo que ocurre en Venezuela no es un accidente, no es una coyuntura, es un proceso histórico, nos guste o no. La universidad autónoma no puede aislarse ni encerrarse en círculos de aristocrático desconsuelo. La ciencia y la técnica son expresiones culturales al servicio de la sociedad, en consecuencia, la universidad debe servirle al pueblo.

Reflexionaba en la Facultad de Ingeniería de LUZ con un excelente grupo de profesores sobre las posibilidades de un estadium superior de relaciones entre LUZ y el Estado. ¿Puede LUZ con sus recursos humanos y científicos ayudar a consolidar el proceso de soberanía petrolera que adelanta la industria petrolera? Por supuesto que si. ¿Pueden nuestras Facultades de Agronomía y Veterinaria apuntalar la soberanía agroalimentaria que se postula estratégicamente? ¿Y la facultad de Ciencias e Ingeniería la soberanía tecnológica? ¿Acaso no tenemos recursos científicos técnicos en la FACES para facilitar los cambios en las microfinanzas, las nuevas formas asociativas cooperativistas, la integración e instrumentos legales para la economía real y financiera? Con conocimiento de causa afirmo que si los tenemos. ¿Me pregunto si nuestra Facultad de Humanidades y Educación puede seguir indiferente frente al proceso de inclusión social educativa que se adelanta vertiginosa y exitosamente desde las misiones? No hay razón, no solo por ser un sin sentido, sino que se le hace un gravísimo daño a los profesionales que egresaran los próximos años descontextualizados del sistema de enseñanza aprendizaje que ha echado andar.

¿Cómo entender que nuestras Facultades de Medicinas y Odontología enajenen solo por conservadurismo e ideología la perspectiva biosicosocial de una medicina de atención primaria, incluyente, justiciera que expresa el proyecto barrio adentro? Los nuevos médicos armados de la ciencia y profundamente humanistas por comprometidos con su patria que atiendan los quebrantos de salud de los pobres y de los trabajadores deberían salir de nuestras aulas y no de otro sitio.

Si la ciencia, la técnica y la cultura están privilegiadamente en nuestras aulas, laboratorios, talleres, bibliotecas, postgrados, equipos humanos porque no ponerlo al servicio del pueblo en combinación armoniosa, respetuosa, consensualizada con el estado. Lo digo de otra manera, con palabras prestadas del Rector Ángel Lombardi: "La Universidad no solo necesita contacto permanente con la ciencia, so pena de anquilosarse. Necesita también contacto con la existencia publica, con la realidad histórica, con el presente que es siempre un integrum y solo se puede tomar en totalidad, sin amputaciones........ La Universidad tiene también que estar abierta a la plena actualidad; mas aun tiene que estar en medio de ella. Y no digo esto solo porque la excitación animadora del aire libre histórico convenga a la Universidad, sino también, viceversa, porque la vida publica necesita urgentemente la intervención en ella de la Universidad como tal".

En esta idea magnifica del Exrector de LUZ se expresa mi convicción como universitario autonomista de siempre. 
Que nadie se confunda. No estamos pidiendo una Universidad subordinada al poder político. No postulamos una Universidad como un vagón más del tren de la revolución bolivariana. Quiero a mi Universidad al frente de la historia, en la locomotora, abrazada a un pueblo sediento de justicia, que reclama construir, en paz y en democracia, una civilización de oportunidades plenas para realizarse en todas las manifestaciones humanas. Quiero a LUZ con la pertinencia social de saberse útil a su pueblo. Una Universidad que con la fuerza creadora de la ciencia, la técnica, la cultura y la crítica ayude a edificar una sociedad humana venezolana plenamente apta para aceptar el desafió del progreso material y humano. En fin, una Universidad involucrada con todos sus átomos con la felicidad del pueblo. Quiero que mi Universidad no le tema al pueblo, que le de la cara, que camine hacia el futuro aferrado a el. Que así sea.

Gracias, muchas gracias por tanta generosidad. 